\title{
Propuesta de una dimensión ética de la investigación
}

DOI: https://doi.org/10.32870/dse.v0i12.268

Vianey de Jesús Mendoza Ruelas*

\section{Reseña}

Sánchez Puentes, Ricardo (2014). Enseñar a investigar, una didáctica nueva de la investigación en ciencias sociales y humanas (4a. ed.). México: ISSUE.

En esta propuesta Sánchez Puentes replantea, evalúa y sugiere estrategias de utilidad en el proceso de enseñanza de la investigación en el ámbito de las ciencias sociales y de las humanidades. Por su análisis, el texto está dirigido esencialmente a quienes se desempeñan como docentes e investigadores. Por la claridad y sencillez de la redacción, es una propuesta que se muestra accesible a aquellos que por primera vez se aproximan al campo de la investigación y su proceso de aprendizaje.

Según explica el propio autor, el presente texto es el resultado de 20 años de dedicación en la labor docente y de investigación. Por su vigencia y pertinencia se realizó una nueva edición actualizada, de acuerdo con el contexto académico e institucional de las escuelas de educación superior en México, principalmente el de la UNAM.

A lo largo de la lectura el autor destaca aportes importantes en el ámbito de la investigación científica social y humanística desde los más contemporáneos como Bunge y Bourdieu, hasta los clásicos como Aristóteles, Kant, Kuhn y Weber, entre otros.

El autor parte de la tesis principal que plantea que la investigación social y de humanidades se debe comprender como un compromiso ético-político y profesional. Lo anterior, en tanto que la investigación es a su vez un proceso de aprendizaje y enseñanza, descripción y explicación de la realidad social; pero también transformación, ya que ofrece maneras de enfrentar y entender aquellas problemáticas sociales que podrían encontrar una solución alternativa. A este respecto afirma, por ejemplo, en relación con la función del tutor, que éste no sólo enseña saberes científicos y prácticos:

El tutor no sólo enseña y transmite saberes teóricos (know that) y saberes prácticos (know how), sino también debe transmitir el significado y los valores últimos del quehacer científico (know why), el por qué o los

* Licenciada en Filosofía y estudiante la licenciatura en Trabajo Social por la Universidad de Guadalajara. Correo electrónico: luzdelunav@outlook.com 
paraqués, de carácter ético-político, de la generación científica... nunca debe omitirse la pregunta sobre los valores de la investigación social y humanística: la defensa de los derechos humanos, el espíritu crítico, y su carácter eminentemente emancipador y libertario (Sánchez, 2014: 17).

Sánchez Puentes nos sugiere que enseñar a investigar es más que una transmisión teórica y estratégica: es un saber práctico y "artesanal” en tanto que se lleva de la mano al aprendiz, imitando el oficio. Es en esa misma formación donde debe enseñarse el valor y la responsabilidad ética del investigador, para que a su vez sepa dar aproximaciones y explicaciones de la realidad social, pero también ofrecer y realizar hallazgos que puedan sugerirse como una forma de intervención dentro de ese contexto social.

El texto se divide en cinco capítulos. En el primero se hace una descripción histórica del ámbito académico y la formación curricular que se ha dado desde el contexto del México de los años sesenta, cómo es que se ha ido rediseñando y retomando la importancia de la investigación en los planes de estudio, para introducir en el perfil del alumno la formación con una inclinación hacia la investigación, no sólo como conocimiento optativo sino como formación obligatoria y profesional.

Caso concreto de lo anterior han sido programas como las becas e intercambios al extranjero o nacionales, las estadías de investigación, el verano de investigación, las olimpiadas y maratones académicos, las tutorías, entre otros. Todo ello tiene la finalidad de hacer de la investigación un aprendizaje significativo; es decir, que trascienda en el alumno como un valor con proyección al futuro y como un posible campo profesional de su interés.

En el capítulo dos se hace una distinción y una insistencia en que la investigación como formación no debe dejarse sólo a nivel de un proyecto de aula. Desde que al aprendiz se le enseña a observar más allá de lo que muestran las apariencias (lo fenoménico), se le van dando pautas e indicadores de aquello que desde la visión cotidiana no le es latente y ni fácil de acceder.

Así pues, el autor destaca que hay que poner el interés en mostrar al aprendiz cómo tener "una mirada científica", alentarlo a trascender la investigación más allá de un trabajo de aula, pues esto es sólo un principio, pero no la única opción. Sánchez Puentes propone que hay que mostrar al alumno la habilidad que tiene de seguir trabajando ese primer acercamiento, de manera tal que en un futuro los resultados del mismo puedan divulgarse y exponerse, quizás como ponencias en algún congreso, para de alguna manera ir alentando y mentalizando al alumno a seguir en este camino de manera seria en su formación.

En el tercer capítulo el autor retoma la tesis inicial y principal de su propuesta: la investigación como una estrategia de cambio social basada en una proyección ético-política como opción. Para ello se señalan nuevas formas de abordar una problemática o fenómeno social que impacte en la procuración ética del bienestar social.

Para lograr el anterior objetivo, Sánchez Puentes destaca que el investigador social y humanista debe tener las nociones de la labor del sociólogo como modelo: el sociólogo como el que dirige 
la mirada observadora y neutral a los fenómenos sociales, el que posteriormente plantea objetivos precisos, el que recolecta datos cuantificables y que va definiendo su propuesta de acuerdo con los estándares institucionales del apoyo que se le ofrece para realizar su investigación. El sociólogo busca, observa, deduce y predice fenómenos y relaciones sociales, para comprender y explicar esa realidad; pero a su vez busca ofrecer su propuesta como transformación y como una visión distinta de dicha perspectiva.

Asimismo, el autor destaca dentro de este capítulo cuáles son algunas de las limitaciones con las que se encuentra un investigador, desde las relacionadas con su campo de especialización hasta las políticas institucionales de donde labora o desarrolla su actividad de investigación.

No se prepara a un investigador universal y cada área, nos dice el autor, posee sus propias delimitaciones. Incluso aquellos paradigmas científicos que rodean nuestro entorno marcan la forma de pensar científicamente. Los valores personales del mismo investigador son líneas que de alguna forma se implican en su proceder, pero el investigador debe ser capaz de neutralizarlos para poder encontrar nuevos hallazgos y replantearlos de la manera más profesional y autentica posible.

En el capítulo cuatro se sintetiza la propuesta pedagógica del autor en cuanto a lo que es la didáctica de la investigación. Esencialmente distingue tres etapas: describir, construir y descubrir. Observar más allá de lo aparente (herencia filosófica de los griegos) y con ello describir la realidad. Construir en tanto que se estructuran los hallazgos de aquello que se encontró en forma latente durante el proceso de investigación. Finalmente descubrir, como investigador, aquellos principios e indicadores que podrían dar lugar a una resignificación de ciertas problemáticas o fenómenos sociales.

En esta última parte Sánchez Puentes nos describe cuál es la responsabilidad más grande del investigador al realizar su labor de divulgación científica, la que detonará la importancia de su trabajo: la redacción de los resultados.

Escribir, como sugiere el autor, es la única forma en que se aprenderá a introducirse en el mundo de la investigación. No hay magia ni trucos, sólo la práctica y la dedicación seria a la revisión de lecturas documentadas de dicha área asegurará al investigador un camino correcto.

Finalmente, el capítulo cinco es, hasta cierto punto, un recuento de todo el material didáctico dado a lo largo de la lectura, y es la parte central y fundamental del libro, pues es donde se retoma la tesis principal que el autor exponía, la de la investigación como un compromiso ético-político de impacto social:

No sólo se busca describir la realidad para detectar regularidades en el comportamiento de la naturaleza y de los individuos; no sólo se intenta explicar esa realidad para hacerla más inteligible y poder servirnos de ella; se busca ante todo y sobre todo construir conceptualmente sistemas de relaciones que nos permitan dominar y transformar la realidad natural y social en aras de un proyecto ético-político de liberación del hombre (Sánchez, 2014: 252). 
Una forma de comprender la relevancia de este proceso es observando ejemplos actuales de nuestro entorno. La investigación desde las ciencias sociales nos permitiría, con base a la observación y clasificación de indicadores de las problemáticas sociales dentro de una comunidad (como los índices de disertación escolar, los niveles de pobreza o la escasa oportunidad laboral), hacer una evaluación de qué aspectos deberían trabajarse en dicho entorno, gestionar recursos para producir campañas de concientización social, aproximarse a un proyecto gubernamental de políticas sociales que permitan hasta cierto grado el desarrollo y por tanto el progreso de esa comunidad y sus problemáticas más demandantes.

La investigación desde las humanidades permitiría, por ejemplo, intervenir dentro de esa misma comunidad, pero en el ámbito educativo; es decir, la investigación de ciertas teorías que pudieran descodificarse en un lenguaje más accesible para aquellos que no son especialistas (como los jóvenes estudiantes); proponer desde el ámbito docente un plan de estudios en un nivel medio básico, que podría tener un impacto positivo en los alumnos; o la investigación como diseño, al elaborar propuestas desde la educación alternativa, basada en destacar la comprensión de valores éticos (la filosofía), la promoción de actividades culturales, aunado a la prevención de conductas antisociales (aportes de las ciencias sociales y de la salud).

Quizás lo anterior permitiría un progreso, o un paso más en materia de una transformación ético-política desde la labor de la investigación social y de humanidades.

En conclusión, el texto de Sánchez Puentes constituye una sólida propuesta porque nos invita a reflexionar sobre la importancia que tiene gestar una dimensión ética como objetivo de la investigación, cómo impactará en nuevas formas de transmitir ese saber y con ello una doble labor del investigador: la divulgación del conocimiento y una propuesta para mejorar, que podría traducise en un bienestar social. 